\title{
An Open Letter to All IJEMM Members on COVID-19
}

\section{Mohammad Yeakub Ali}

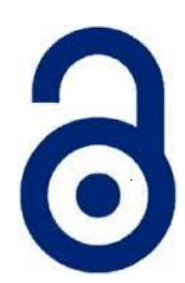

Received: 24 March 2020

Accepted: 26 March 2020

Published: 30 March 2020

Publisher: Deer Hill Publications

(C) 2020 The Author(s)

Creative Commons: CC BY 4.0

\section{Dear IJEMM Members}

I wanted to provide an update to the broader community of International Journal of Engineering Materials and Manufacture (IJEMM) regarding our efforts to alleviate the spread of the COVID-19 coronavirus.

The Editorial Board is deeply sympathised with the people suffering worldwide due the outbreak of pandemic COVID-19. We are closely monitoring the outbreak and implementing social isolation and other measures, according to World Health Organisation guidelines, to mitigate the impact on our members, volunteers and customers around the world. As the safety of people is of highest priority, our aim is to continue delivering our services for editors, reviewers, authors, readers, and other members to the highest possible standards using our online web-based platforms.

I trust that each of you is doing well and finding ways to cope with this challenging pandemic situation which is a test from God, the almighty. Please stay safe, do not panic, heighten your spirituality and seek forgiveness.

With thanks and regards,

\section{Professor Ir. Dr. Mohammad Yeakub Ali}

Editor-In-Chief

International Journal of Engineering Materials and Manufacture

\author{
M. Y. Ali $ه$ \\ Mechanical Engineering Programme Area \\ Faculty of Engineering, Universiti Teknologi Brunei \\ Tungku Highway, Gadong, Bandar Seri Begawan BE1410, Brunei Darussalam \\ E-mail: yeakub.ali@utb.edu.bn
}

